\title{
PEMANFAATAN ARANG AKTIF SABUT KELAPA SAWIT SEBAGAI ADSOBEN ZAT WARNA SINTETIS REACTIVE RED-120 DAN DIRECT GREEN -26
}

\author{
Melfi Puspita*1, M. Lutfi Firdaus ${ }^{2}$, Nurhamidah ${ }^{3}$ \\ Program Studi Pendidikan Kimia Fakultas Keguruan dan Ilmu Pendidikan Universitas Bengkulu \\ ${ }^{1,2,3}$ Program Studi Pendidikan Kimia, Jurusan PMIPA, FKIP, Universitas Bengkulu \\ *1e-mail: melfipuspita@gmail.com
}

\begin{abstract}
The problem of environmental polution caused by waste of batik industry lately is increasing, so it needed a method to overcome that problem. The aim of this study was to determine the ability of activated charcoal from coconut fiber palm in adsorbing Reactive Red-120 and Direct Green-26 dyes in waste of batik along with determining the parameters of isotherms adsorption using UV-Vis Spectrophotometer analysis method. Variations of $\mathrm{pH}$, contact time, adsorbent weight and temperature were carried out as variable to obtain optimum conditions of the adsorption process. The optimum of conditions for Reactive Red-120 occured at $\mathrm{pH} 3$ and a contact time of 30 minutes, while Direct Green-26 occurred at $\mathrm{pH} 4$ and a contact time of 40 minutes, with each adsorbent weight $150 \mathrm{mg}$ and the temperature $30^{\circ} \mathrm{C}$. Adsorption isotherms determined by Freundlich and Langmuir models with maximum adsorption capacity $\left(\mathrm{Q}_{\max }\right)$ were obtained for the Reactive Red-120 was 400 $\mathrm{mg} / \mathrm{g}$, while Direct Green-26 is $169 \mathrm{mg} / \mathrm{g}$.
\end{abstract}

Keywords : Activated charcoal, coconut fiber palm, reactive red-120, direct green-26

\begin{abstract}
Abstrak
Masalah pencemaran lingkungan yang disebabkan limbah industri batik belakangan ini semakin meningkat, sehingga dibutuhkan suatu metode untuk menanggulangi masalah tersebut. Penelitian ini bertujuan untuk mengetahui kemampuan arang aktif yang dibuat dari sabut kelapa sawit (AASKS) untuk mengadsorpsi zat warna Reactive Red-120 dan Direct Green-26 dalam limbah batik beserta penentuan parameter isoterm adsorpsi menggunakan metode analisis Spektrofotometer UV-Vis. Variabel penelitian adalah berupa variasi $\mathrm{pH}$ larutan, waktu kontak, berat adsorben dan suhu yang dilakukan untuk mendapatkan kondisi optimum proses adsorpsi. Kondisi optimum adsorpsi zat warna Reactive Red - 120 terjadi pada pH 3 dan waktu kontak 30 menit, sedangkan Direct Green -26 terjadi pada pH 4 dan waktu kontak 40 menit, dengan masing-masing berat adsorben $150 \mathrm{mg}$ dan suhu $30{ }^{\circ} \mathrm{C}$. Isoterm adsorpsi ditentukan melalui model Freundlich dan Langmuir dengan kapasitas adsorpsi maksimum $\left(\mathrm{Q}_{\max }\right)$ AASKS yang diperoleh untuk Reactive Red-120 adalah $400 \mathrm{mg} / \mathrm{g}$ sedangkan Direct Green-26 adalah $169 \mathrm{mg} / \mathrm{g}$.
\end{abstract}

Kata kunci : Arang aktif, sabut kelapa sawit, reactive red-120, direct green-26

\section{PENDAHULUAN}

Berbagai bahan kimia digunakan dalam pembuatan batik antara lain zat warna seperti zat warna asam, basa, direk, reaktif, naphtol dan bejana. Semua buangan cair yang berasal dari hasil kegiatan proses produksi batik yang tidak digunakan lagi disebut limbah cair industri [1]. Jika limbah cair yang dihasilkan dari proses produksi batik dibuang langsung ke lingkungan tanpa dilakukan pengolahan terlebih dahulu, maka dapat menyebabkan pencemaran lingkungan terutama ekosistem perairan [2].

Untuk menanggulangi masalah pencemaran lingkungan yang disebabkan senyawa dari zat warna industri batik telah dikembangkan berbagai metode diantaranya, koagulasi, oksidasi, ozonisasi dan adsorbsi. Proses adsorpsi dapat menggunakan berbagai macam adsorben seperti zeolit, silika gel, arang aktif, kitosan dan bentonit [3]. Arang aktif adalah arang yang pori-porinya terbuka, sehingga memiliki daya adsorpsi tinggi, sehingga banyak digunakan dalam proses pemurnian air, gas, larutan atau cairan, safety mask dan respirator, industri nuklir, penyerap rasa dan bau pada air, penghilang senyawa organik dalam air dan masih banyak manfaat lainnya. Salah satu material yang dapat digunakan untuk membuat arang aktif adalah limbah dari kelapa sawit berupa sabut, karena kandungan selulosa, hemiselulosa dan lignin yang cukup tinggi, karena itu diperkirakan dapat dibuat menjadi arang aktif karena banyak mengandung unsur karbon[4,5].

Banyak aspek yang dapat mempengaruhi adsorpsi zat warna oleh arang aktif seperti, $\mathrm{pH}$ media, waktu kontak, berat adsorben, dan suhu, dimana jika adsorpsi dilakukan pada kondisi optimum untuk setiap aspeknya maka proses adsorpsi akan terjadi secara maksimal, sehingga zat warna yang terserap akan semakin banyak yang berarti daya serap dari arang aktif menjadi semakin besar. Hal inilah yang mendasari mengapa $\mathrm{pH}$, waktu kontak, berat adsor- 
ben dan suhu optimum itu sangat penting untuk ditentukan.

Proses adsorpsi biasanya diikuti dengan pengamatan isoterm, kinetika dan termodinamika adsorpsi. Isoterm adsorpsi adalah hubungan kesetimbangan antara fase cair (adsorbat) dan konsentrasi di dalam partikel adsorben pada suhu tertentu. Termodinamika menunjukkan keadaan akhir dari proses adsorpsi, sedangkan kinetika ditentukan untuk mengetahui perubahan adsorpsi terhadap waktu. Dengan mengetahui aspek-aspek tersebut maka akan diketahui bagaimana mekanisme proses adsorpsi itu berlangsung. Ini semua berhubungan dengan efektivitas dan efisiensi arang aktif dalam mengadsorpsi.

Penelitian ini bertujuan utuk menentukan kemampuan arang aktif dalam mengadsorpsi zat warna sintetis dan berapakah $\mathrm{pH}$, waktu kontak, berat adsorben dan suhu optimum pada adsorpsi zat warna oleh arang aktif sabut kelapa sawit (AASKS).

\section{METODE PENELITIAN}

Pada penelitian ini variasi yang digunakan untuk menentukan proses adsorpsi zat warna adalah pH larutan, waktu kontak, berat adsorben dan suhu. Penentuan $\mathrm{pH}$ optimum dilakukan untuk mengetahui pada $\mathrm{pH}$ berapa arang aktif memiliki daya serap paling besar terhadap zat warna. Variasi $\mathrm{pH}$ yang digunakan berturut-turut $\mathrm{pH} 2,3,4,5,6,7$ dan 8 Penentuan $\mathrm{pH}$ optimum dilakukan dengan mengambil larutan standar zat warna Reactive Red-120 dan Direct Green-26 konsentrasi 100 ppm masing masing $10 \mathrm{~mL}$ lalu dimasukkan ke dalam botol vial. Mengatur $\mathrm{pH}$ dengan penambahan $\mathrm{NaOH}$ dan $\mathrm{HCl}$ menjadi $\mathrm{pH}$ 2, 3, 4, 5, 6, 7, dan 8, lalu ditambahkan AASKS sebanyak $100 \mathrm{mg}$ ke dalam masing-masing larutan. Campuran tersebut dengan menggunakan shaker selama 60 menit pada suhu kamar dengan kecepatan $150 \mathrm{rpm}$.

Waktu kontak optimum ditentukan dengan cara mengambil larutan standar zat warna Reactive Red-120 dan Direct Green-26 konsentrasi 100 ppm masing-masing $10 \mathrm{~mL}$. Dimasukkan ke dalam botol vial, kemudian ditambahkan AASKS sebanyak 100 mg pada suhu kamar. Diaduk menggunakan shaker dengan variasi waktu kontak selama 10, 20, 30, 40, 60, dan 90 menit.

Berat adsorben optimum ditentukan dengan cara mengambil larutan standar zat warna Reactive Red-120 dan Direct Green-26 konsentrasi 100 ppm masing-masing $10 \mathrm{~mL}$ dengan menggunakan pipet ukur. Lalu diatur pada $\mathrm{pH}$ optimum dan masukkan ke dalam botol vial. Kemudian ditambahkan AASKS dengan variasi berat 50, 75, 100, 125, 150, dan 175 mg. Diaduk campuran menggunakan shaker selama waktu kontak optimum pada suhu kamar.
Penentuan pengaruh suhu terhadap proses adsorpsi dilakukan dengan mengambil $10 \mathrm{~mL}$ larutan warna Reactive Red -120 konsentrasi 100 ppm menggunakan pipet ukur, lalu diatur pada $\mathrm{pH}$ optimum. Diberi variasi suhu dengan cara pemanasan pada suhu $30{ }^{\circ} \mathrm{C}, 40{ }^{\circ} \mathrm{C}$ dan $50^{\circ} \mathrm{C}$. Ditambah berat AASKS optimum dan diaduk menggunakan shaker dengan kecepatan 150 rpm selama waktu kontak optimum.

Untuk mengetahui kapasitas adsorpsi maksimum dengan cara diambil $10 \mathrm{~mL}$ menggunakan pipet ukur larutan Reactive red-120 dan Direct green-26 masing - masing dengan variasi konsentrasi yaitu 25, 50, 75, 100, 125, 150, 250, 500 dan 1000 ppm yang telah diatur pada $\mathrm{pH}$ optimum. Ditambah AASKS dengan berat optimum dan diaduk menggunakan shaker dengan kecepatan 150 rpm dalam waktu kontak optimum.

\section{HASIL DAN PEMBAHASAN}

Hasil yang diperoleh dari penentuan $\mathrm{pH}$ optimum dapat dilihat pada Gambar 1 berikut ini :

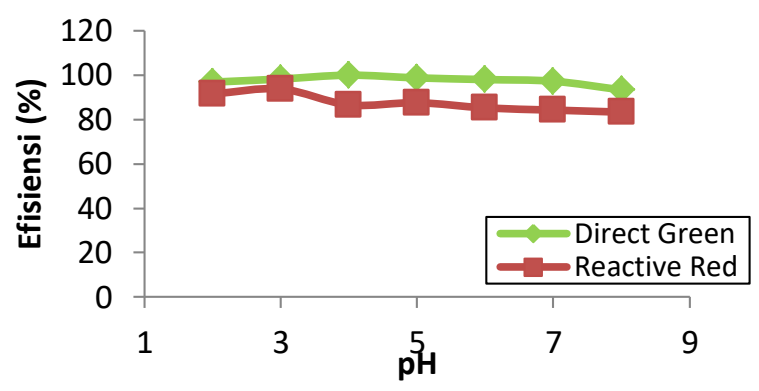

Gambar 1. Kurva Adsorpsi zat warna pada Variasi $\mathrm{pH}$

Gambar 1 memperlihatkan bahwa adsorpsi optimum AASKS terhadap kedua zat warna terjadi pada pH asam. Pada Direct Green-26 adsorpsi optimum AASKS terjadi pada $\mathrm{pH} 4$, dan untuk Reactive Red-120 terjadi pada $\mathrm{pH} 3$. Pengaruh $\mathrm{pH}$ asam larutan terhadap adsorpsi zat warna kemungkinan dikarenakan adanya gaya antara arang aktif dengan zat warna, dimana $\mathrm{H}^{+}$dari zat warna akan memprotonasi $\mathrm{OH}^{-}$dari gugus aktif adsorben $(\mathrm{COOH})$ menjadi $\mathrm{H}_{2} \mathrm{O}^{+}$, gugus inilah yang nantinya akan berikatan dengan gugus sulfonat terdissosasi $\left(\mathrm{SO}_{3}{ }^{-}\right)$ pada zat warna. Kemungkinan gaya yang terjadi antara arang aktif dengan zat warna Direct Green-26 dan Reactive Red-120 adalah gaya Van der Waals [6], seperti yang terlihat pada Gambar 2 dan 3.

Waktu kontak optimum merupakan waktu yang dibutuhkan arang aktif untuk menyerap zat warna secara optimal. pada $\mathrm{pH}$ optimum yang didapat kan pada percobaan sebelumnya. Dari percobaan tersebut didapatkan kurva hubungan efisiensi terhadap waktu. 


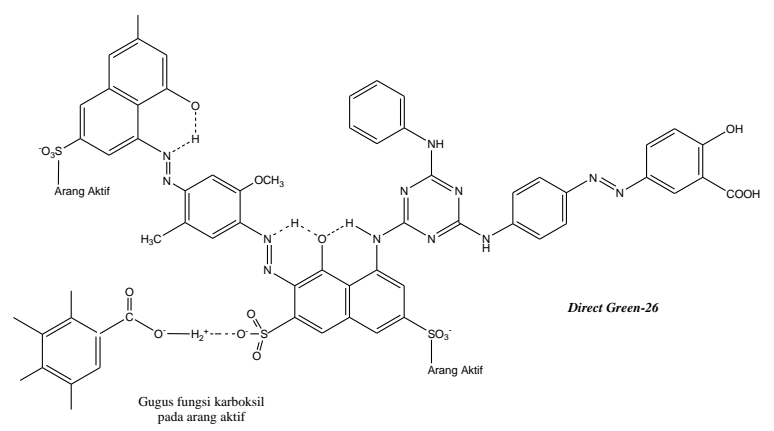

Gambar 2. Kemungkinan Ikatan Arang Aktif dengan Direct Green-26

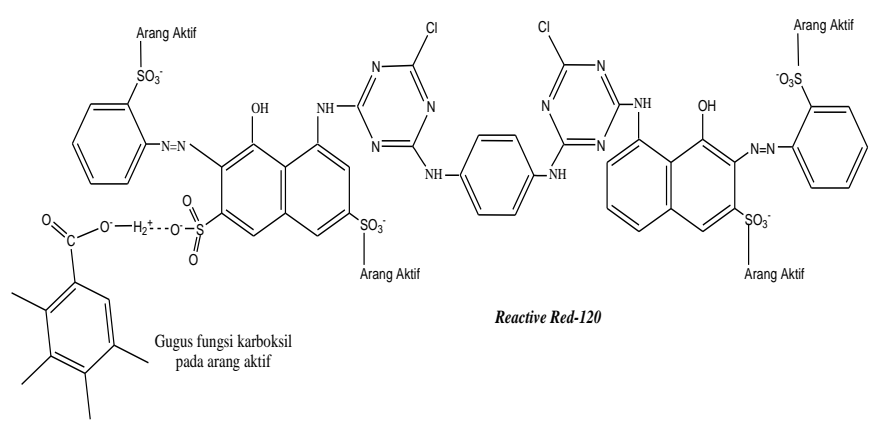

Gambar 3. Kemungkinan Ikatan Arang Aktif dengan Reactive Red-120

Dari Gambar 4 di bawah ini dapat diketahui bahwa waktu kontak optimum Direct Green-26 terjadi pada waktu 40 menit, sedangkan Reactive Red120 waktu kontak optimumnya adalah 30 menit. Pada awal adsorpsi laju berlangsung cepat karena seluruh permukaan pori masih kosong dan molekul zat warna akan menempel dan membentuk suatu lapisan pada permukaan. Namun setelah waktu kontak semakin lama permukaan yang kosong akan semakin berkurang sehingga kemampuan adsorben untuk menyerap molekul zat warna menurun, bersamaan dengan ini laju pelepasan kembali molekul zat warna justru meningkat hingga mencapai suatu kesetimbangan. Dengan kata lain, pada kondisi ini proses adsorpsi dan desorpsi adalah sama [7]. Hal itulah yang mendasari mengapa waktu kontak sangat berpengaruh terhadap proses adsorpsi.

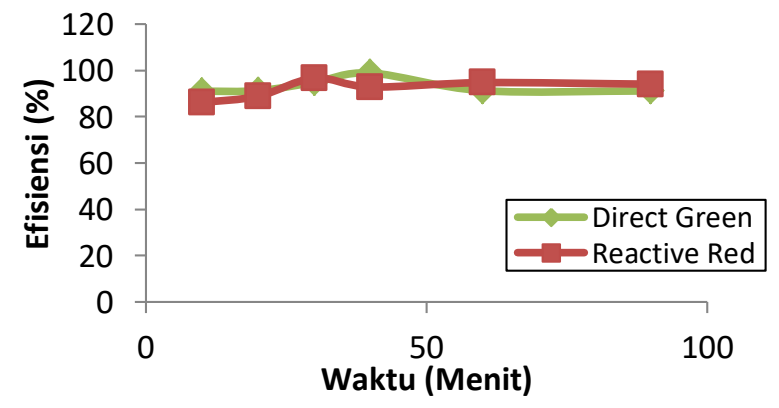

Gambar 4. Kurva adsorpsi zat warna pada variasi waktu
Dari Gambar 5 dapat diketahui bahwa penambahan AASKS akan meningkatkan daya serap terhadap zat warna. Hal ini dikarenakan penambahan arang aktif akan menyebabkan peningkatan luas permukaan yang berarti akan semakin banyak pula sisi aktif dari arang aktif yang dapat menyerap zat warna. Tetapi daya serap AASKS juga dapat mengalami penurunan ketika telah mencapai titik kesetimbangan, sehingga pada penambahan $175 \mathrm{mg}$ daya serap zat warna mengalami penurunan. Zat warna Reactive Red-120 dan Direct Green-26 memiliki berat adsorben optimum yang sama yaitu $150 \mathrm{mg}$. Variasi suhu yang digunakan pada Penentuan suhu optimum penelitian ini adalah 303, 313 dan $323 \mathrm{~K}$.

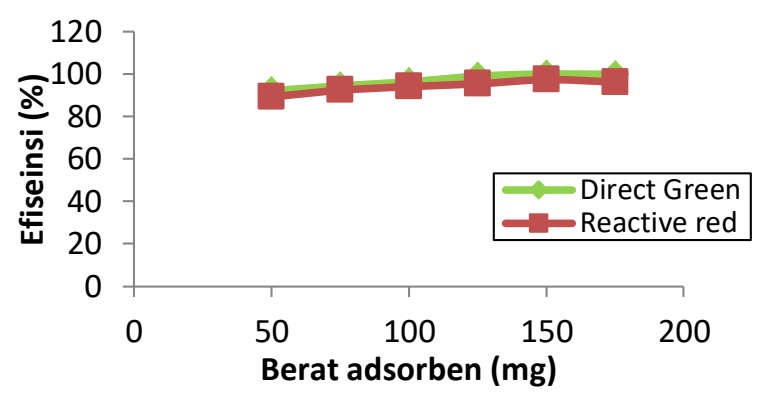

Gambar 5. Kurva adsorpsi zat warna pada variasi berat adsorben

Gambar 6 menunjukkan bahwa daya serap arang aktif terhadap zat warna Reactive Red-120 dan Direct Green-26 paling besar yaitu pada suhu $303 \mathrm{~K}$. Seiring kenaikan suhu adsorpsi zat warna terus mengalami penurunan daya serap yang dikarenakan semakin tinggi suhu maka semakin besar rata-rata energi kinetik, sehingga partikel-partikel di dalam larutan akan bergerak lebih cepat yang mengakibatkan adsorbat yang telah berhasil diserap akan terlepas kembali dari pori-pori arang aktif.

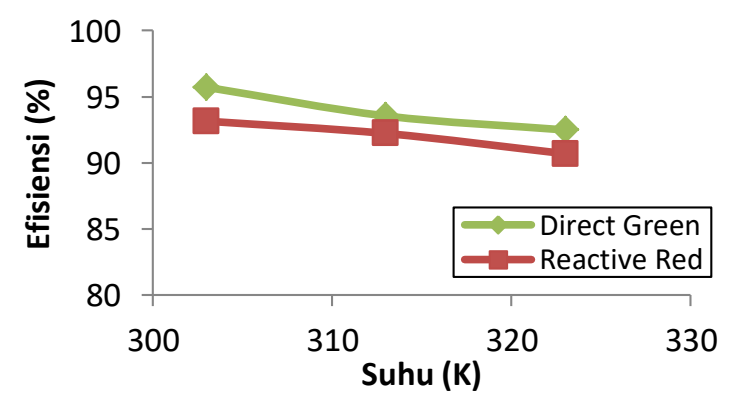

Gambar 6. Kurva adsorpsi zat warna pada variasi suhu.

Model isoterm yang digunakan untuk menentukan pola adsorpsi zat warna Reactive Red-120 dan Direct Green-26 pada permukaan AASKS 
adalah model Freundlich dan model Langmuir. Penentuan model isoterm tergantung pada nilai koefisien determinasi $\left(\mathrm{R}^{2}\right)$ dengan nilai yang paling besar.

Pada penelitian ini proses adsorpsi kedua zat warna mengikuti model Freundlich yang didasarkan atas terbentuknya lapisan multilayer oleh molekulmolekul adsorbat pada permukaan adsorben dan adsorpsi berlangsung secara fisika (fisisorpsi). Sedangkan proses adsorpsi model Langmuir berlangsung secara kimia (kemisorpsi) dan didasarkan pada terbentuknya lapisan monolayer pada permukaan adsorben, sehingga dapat disimpulkan bahwa proses adsorpsi zat warna Reactive Red-120 dan Direct Green-26 berlangsung secara fisisorpsi. Ikatan yang terjadi pada mekanisme fisisorpsi itu biasanya lemah, karena hanya terikat oleh gaya Van der Waals..

Dari hasil uji penentuan kapasitas adsorpsi AASKS terhadap zat warna Reactive Red-120 dan Direct Green-26 dapat dilihat pada Tabel 1.

Tabel 1. Kapasitas adsorpsi AAKS terhadap Reactive Red120 dan Direct Green-26.

\begin{tabular}{ccc}
\hline Jenis Adsorben & Zat warna & $\begin{array}{c}\mathrm{Q}_{\max } \\
(\mathrm{mg} / \mathrm{g})\end{array}$ \\
\hline Sabut Kelapa Sawit & Reactive Red-120 & 400 \\
\hline Sabut Kelapa Sawit & Direct Green-26 & 169.5 \\
\hline
\end{tabular}

Tabel 1 menunjukkan bahwa arang aktif dari sabut kelapa sawit memiliki daya serap maksimum yang cukup baik, dimana untuk Reactive Red-120 daya serap mencapai $400 \mathrm{mg} / \mathrm{g}$ dan untuk Direct Green-26 mencapai $169.49 \mathrm{mg} / \mathrm{g}$ yang berarti me-nyamai karbon aktif standard (merck) [8] dan lebih baik dari adsorben kitosan [9] . Zat warna Reactive Red-120 lebih banyak terserap daripada Direct Green-26 dikarenakan strukturnya yang memanjang sehingga lebih mudah membentuk dipol sesaat pada molekul [10].

\section{KESIMPULAN}

Berdasarkan penelitian yang telah dilakukan dapat disimpulkan bahwa : Arang aktif sabut kelapa sawit mampu mengadsorpsi zat warna Reactive Red dan Direct Green dengan daya serap yang dimiliki sebesar $32 \mathrm{mg} / \mathrm{g}$ untuk Reactive Red sedangkan untuk Direct Green sebesar $27 \mathrm{mg} / \mathrm{g}$. pH larutan optimum untuk adsorpsi zat warna Reactive Red dan Direct Green oleh arang aktif sabut kelapa sawit berturut-turut adalah pada $\mathrm{pH} 3$ dan $\mathrm{pH} 4$. Waktu kontak optimum adsorpsi zat warna oleh arang aktif untuk Reactive Red terjadi pada waktu 30 menit sedangkan Direct Green terjadi pada waktu 40 menit. Berat adsorben optimum arang aktif untuk meng- adsorpsi zat warna Reactive Red dan Direct Green adalah $150 \mathrm{mg}$. Suhu larutan optimum zat warna Reactive Red dan Direct Green dalam proses adsorpsi adalah $30{ }^{\circ} \mathrm{C}$.

\section{SARAN}

Pembuatan arang aktif dalam ukuran nano perlu dicoba untuk meningkatkan daya serap arang aktif. Mencoba memodifikasi arang aktif dengan materi lain untuk meningkatkan daya serap arang terhadap zat warna.

\section{DAFTAR PUSTAKA}

[1] Kusmiyati, R.I Setyawan, D. Vitasari, A.M Fuadi, 2009. Kinetika dan Termodinamika Adsorpsi Vertigo Blue 49 dengan Adsorben Karbon Aktif Arang Batu Bara. Simposium Nasional RAPI VIII Desember 2009, Fakultas Teknik UMS, Surakarta.

[2] Kurniawan, M W., Purwanto dan Sudarno. 2013. Kajian Pengelolaan Air Limbah Sentra Industri Kecil Dan Menengah Batik Dalam Perspektif Good Governance Di Kabupaten Sukoharjo. Prosiding Seminar Nasional Pengelolaan Sumberdaya Alam Dan Lingkungan 2013.

[3] Muna, N. 2014. Adsorpsi Zat Warna Malachite Green (MG) Oleh Komposit Kitosan-Bentonit. Skripsi: Program Studi Kimia Fakultas Sains dan Teknologi Universitas Islam Negeri Sunan Kalijaga.

[4] Pakpahan, Iyung. 2006. Panduan Lengkap Kelapa Sawit. Penebar Swadaya : Jakarta.

[5] Muthia, F. 1998. Pembuatan Arang Aktif Dari Sabut Kelapa Sawit Sebagai Bahan Penjernih Air. Tugas Akhir Fakultas Teknologi Pertanian, Institut Pertanian Bogor.

[6] Herlina, A. 2012. Perbandingan Pemanfaatan Kitosan dan Arang Aktif Sebagai Adsorben Zat Warna Remazol Violet Dan Remazol Blue. http://repository.unib.ac.id.

[7] Tabak, A. Baltas N, Afsin, B, Emirik, M, Caglar, B, Eren, E,. 2010. Adsorption of Reactive Red 120 from Aqueous Solutions by Cetylpiradinium-bentonit. Journal Chemistry Technology Biotechnology, 85: 1199-1207.

[8] Kharaisheh,MAM., Al-Degs,Y.S., Allen,S.J., Ahmad,M.N, . 2002. Elucidation on controlling steps of reactive dye adsorption on activated carbon. Journal of Industrial and Engineering Chemistry Research. 41 : 1651-1657. 
[9] Annadurai., G, Ling, LY, Lee, JF, 2008. Adsorption of Reactive Dye from an Aqueous Solution by Chitosan: Isotherm, Kinetic and Thermodynamic Analisys. Journal of Hazardous Materials. 152:337-346.

[10] Syarifuddin, Nuraini. 1994. Ikatan Kimia. Gadjah Mada University Yogyakarta
Penulisan Sitasi Artikel ini ialah :

Puspita, M, Firdaus, M.L, Nurhamidah, 2017, Pemanfaatan Arang Aktif Sabut Kelapa Sawit Sebagai Adsorben Zat Warna Sintetis Reactive Red120 dan Direct Green-26, Alotrop, 1(1):75-79. 